ARMA 14-7072

\title{
On the water retention behaviour of shales
}

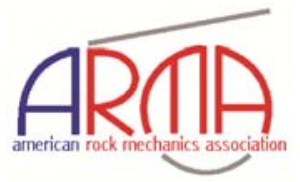

\author{
Ferrari A., Favero V. and Laloui L. \\ Laboratory for Soil Mechanics (LMS), Ecole Polytechnique Fédérale de Lausanne (EPFL), Switzerland
}

Copyright 2013 ARMA, American Rock Mechanics Association

This paper was prepared for presentation at the $47^{\text {th }}$ US Rock Mechanics / Geomechanics Symposium held in San Francisco, CA, USA, 23-26 June 2013.

This paper was selected for presentation at the symposium by an ARMA Technical Program Committee based on a technical and critical review of the paper by a minimum of two technical reviewers. The material, as presented, does not necessarily reflect any position of ARMA, its officers, or members. Electronic reproduction, distribution, or storage of any part of this paper for commercial purposes without the written consent of ARMA is prohibited. Permission to reproduce in print is restricted to an abstract of not more than 200 words; illustrations may not be copied. The abstract must contain conspicuous acknowledgement of where and by whom the paper was presented.

\begin{abstract}
Shales are among the most considered geomaterials in current energy-related geomechanical investigations; they are involved in engineering applications such as the unconventional extraction of natural gas, $\mathrm{CO} 2$ sequestration and nuclear waste geological storage. A deep understanding of their behaviour with regard to variations in the degree of saturation is of primary significance for such applications. This paper illustrates the advances in the experimental analysis of the water retention behaviour of shales under non-isochoric conditions which have been recently achieved by the authors. The testing methodologies involve the direct control of the water content and the subsequent measurement of the total suction at equilibrium by a psychrometer. Furthermore, the volume change response of the material upon total suction variations can be investigated: a fluid displacement technique with a non-polar liquid is used in order to assess the volume changes of the shale samples and to compute the degree of saturation. The results highlight the important features of the retention behaviour of shales, such as the existence of main wetting and drying paths, the hysteresis domain and the scanning behaviour. Selected results are presented for three shales from the northern region of Switzerland.
\end{abstract}

\section{INTRODUCTION}

The development of engineering activities involving shales such as the extraction of shale gas and shale oil, the geological storage of nuclear waste and $\mathrm{CO}_{2}$ sequestration, has led to an increasing interest in the geomechanical behaviour of these geomaterials. In the context of such engineering applications, a deep understanding of shale retention behaviour is of a great importance. Water retention mechanisms play a major role in fluid trapping due to the capillary forces in the two-phase flows in gas reservoirs as well as in the resaturation of shale formations after ventilation, as in the case of deep geological repositories.

This paper presents the advanced experimental techniques that have been recently developed by the authors for testing the water retention behaviour of shales. Testing procedures are conceived with the aim of creating a standard protocol to tackle the determination of the wetting and drying paths of the shale water retention behaviour. The methodologies are based on the direct control of the shale water content and on the subsequent measurement of the total suction at equilibrium by a psychrometer. The swelling/shrinkage of shale is related to suction, or the degree of saturation variations; in order to investigate the volume change response of the material upon total suction variations, a fluid displacement technique with a non-polar liquid is used. The technique allows to assess the changes in void ratio of the shale specimens and to compute the degree of saturation. The retention behaviour of the material is investigated along main wetting and drying paths as well as along scanning paths. This analysis highlights the fact that attention must be paid when wetting the shale, starting from its "as-extracted" state since the registered water contents may not be referred to a main wetting path.

\section{TESTED SHALES}

The shales considered in the present study come from the northern region of Switzerland: the "Opalinus Clayshallow" (OPA-shallow) sample was obtained at the Mont Terri Underground Laboratory from the shaly facies; the "Brown Dogger" (BD-deep) (depth of 766.67 - $807.44 \mathrm{~m}$ ) and the "Opalinus Clay-deep" (OPA-deep) (depth of $837.44-891.25 \mathrm{~m}$ ) were extracted from a deep geothermal well near the village of Schlattingen in the Molasse Basin.

The geotechnical characterization consists in the determination of the particle density $\left(\rho_{\mathrm{s}}\right)$, the bulk density $(\rho)$, the water content $(\mathrm{w})$, the void ratio (e), the degree of saturation $\left(\mathrm{S}_{\mathrm{r}}\right)$ and the Atterberg limits (the 
liquid limit $\mathrm{w}_{\mathrm{L}}$ and the plastic limit $\mathrm{w}_{\mathrm{P}}$ ). The results of the geotechnical identification of the cores are reported in Table 1 while Fig. 1 depicts the grain size distributions of the considered shales [1].

Table 1: Geotechnical characterization of the tested shales

\begin{tabular}{|l|c|c|c|}
\hline Shale & OPA-shallow & BD-deep & OPA-deep \\
\hline \hline$\rho_{s}\left(\mathrm{Mg} / \mathrm{m}^{3}\right)$ & 2.74 & 2.72 & 2.72 \\
\hline$\rho\left(\mathrm{Mg} / \mathrm{m}^{3}\right)$ & 2.46 & $2.52-2.56$ & $2.49-2.55$ \\
\hline$w(\%)$ & 6.9 & $2.7-4.4$ & $3.3-4.9$ \\
\hline$e(-)$ & 0.21 & $0.09-0.12$ & $0.09-0.15$ \\
\hline$S_{r}(\%)$ & 92 & $69-99$ & $80-96$ \\
\hline$w_{L}(\%)$ & 38 & $25-33$ & $29-39$ \\
\hline$w_{P}(\%)$ & 23 & $10-23$ & $19-25$ \\
\hline
\end{tabular}

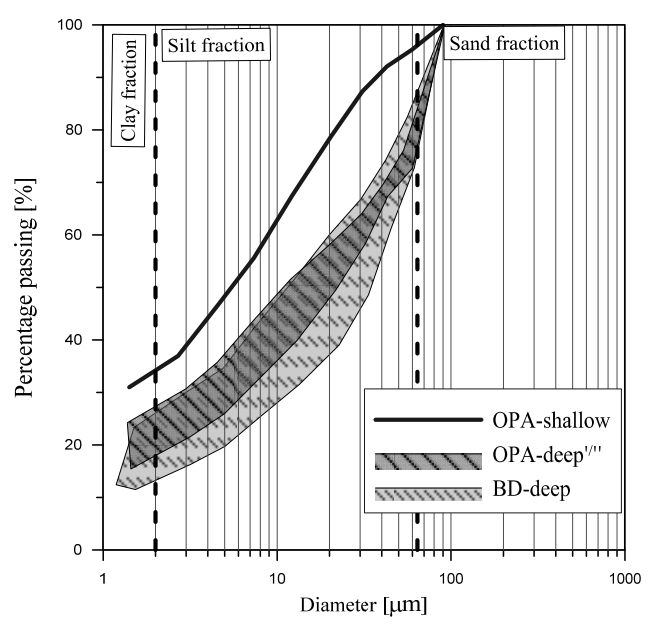

Fig.1. Grain size distribution of the tested shales.

The pore size density (PSD) function of the tested shale cores is determined through the Mercury Intrusion Porosimetry (MIP); this technique consists in forcing the penetration of mercury into a sample and in measuring the intruded volume of mercury as a function of the applied pressure. The required pressure is inversely proportional to the size of the progressively filled pores.

The obtained results are presented in Fig.2. The PSD functions are found to be unimodal for all the tested shales; they show pore modes at approximately $20 \mathrm{~nm}$ for the OPA-shallow and BD-deep and at $8 \mathrm{~nm}$ for the OPA-deep.

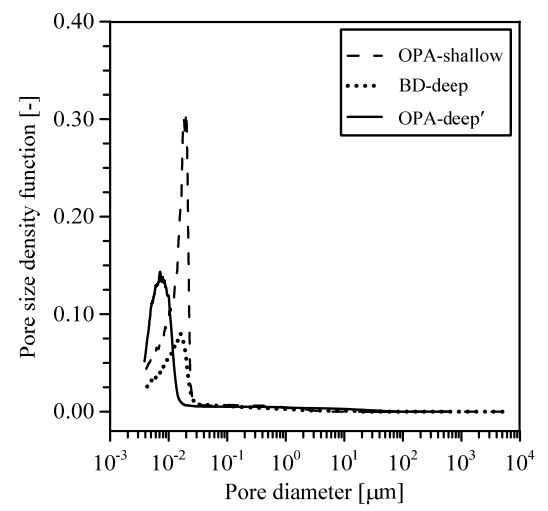

Fig.2. Pore size density function of the tested shales.

\section{TESTING METHODOLOGIES}

This section describes the experimental methodologies established to analyse the water retention behaviour of shales under unstressed conditions. In all the depicted testing procedures, synthetic waters are used with the aim of reproducing the in-situ pore water composition $[2,3]$. The osmotic suctions of the synthetic waters used are measured by a dew-point psychrometer and result in values of $1.2 \mathrm{MPa}$ for the OPA sample and $0.98 \mathrm{MPa}$ for the BD-deep and OPA-deep samples.

The presented testing techniques are based on the direct control of the water content and on the subsequent measurement of the total suction value [4]. The imposed water content is applied differently for the wetting and drying paths. The total suction readings are carried out by means of a dew-point psychrometer (Decagon, WP4c) $[5,6]$. The apparatus gives indirect measures of the total suction of a sample by reading the relative humidity established by the sample in a closed environment. The chilled-mirror dew point technique is used to measure the relative humidity. The total suction is then obtained by the psychrometric law [7] which relates the relative humidity $(\mathrm{RH})$ and the absolute temperature $(\mathrm{T})$ to the total suction $(\psi)$ :

$\psi=-\frac{\rho_{w} R T}{M_{w}} \ln (R H)$

where $R$ is the universal gas constant and $\rho_{\mathrm{w}}$ and $\mathrm{M}_{\mathrm{w}}$ are the density and the molecular mass of water, respectively.

The first step of the testing procedure requires the cutting of slices measuring $7-8 \mathrm{~mm}$ in height from the shale core; one slice is divided into five parts and each part is then divided into three specimens of about $2 \times 2 \times 1$ $\mathrm{cm}^{3}$. The three central specimens are immediately tested by means of the WP4c in order to obtain the initial conditions of the material. After the determination of the total suction, the volume of the specimens is measured. Indeed, the computation of the degree of saturation requires the measurement of the volume of the shale samples at each equilibrated state.

The method adopted for the volume measurement is based on a fluid displacement technique which uses pycnometers filled with kerdane, a paraffin oil used for its immiscibility with water and its ability to invade the air-filled pore spaces in the surface without affecting the soil structure [8]. After the determination of the initial conditions of the tested shales, the main wetting and drying paths can be determined.

The determination of the main drying path requires the initial wetting of the core slices which is achieved through the use of a sealed-glass jar filled by synthetic water. The slices are placed on filter papers, which in 
turn are placed on a porous stone; the latter is immersed in the synthetic water thus the material is wetted by capillary action allowing the volume changes of the samples. This equalized condition is referred as "zero matric suction" state". In order to assess the equalization of internal humidity, the weight evolution over time is monitored. Nearly two weeks are required for the slices to equalize. The wetted slices are then divided in small parts measuring approximately $20 \times 20 \times 8 \mathrm{~mm}^{3}$. Each part is placed in a desiccator and dried for the amount of time necessary to achieve the target water content of that particular part. After the drying step, the samples are packed for at least three days to allow for the internal redistribution of water.

In order to reproduce the main wetting path, the shale samples have to reach an initial dry state. This is obtained by placing the core slices in a desiccator containing silica gel. The material is left to dry for approximately three weeks (applied total suction of approximately $270 \mathrm{MPa}$ ) until no significant change in their weight is detected. The slices are then cut in pieces and a certain amount of synthetic water is added to each part to obtain the target water content. Each part is then placed in a hermetic container and let to reach internal equilibrium of water content as in the case of the main drying path.

Once internal equilibrium is reached for the tested samples, the total suction is measured through the dewpoint psychrometer. The last step consists in the measurement of the sample volume thus the void ratio and the degree of saturation of the considered shale sample can be evaluated and related to the measured total suction. The technique used for the volume measurement is destructive; for such reason each point of the main drying and wetting paths correspond to a different shale specimen. When the retention behaviour is sought only in terms of water content or when a limited amount of core material is available, a different procedure is considered. This latter technique consists of a progressive drying or wetting of the same shale specimen; the water content control is performed following the procedure that has been previously described. As no volume measurement is conducted, the specimen can be equalized to a new target water content after the total suction for the previous step has been measured.

\section{RESULTS}

The results obtained in the determination of the main wetting and drying paths are shown in Fig.3, Fig.4 and Fig. 5 in term of water content and degree of saturation versus total suction for the Opalinus Clay-shallow, the BD-deep and the Opalinus Clay-deep respectively. The points reported in the graphs represent a measurement which corresponds to the average of three specimens, each of which followed an identical drying/wetting path. The initial state of each material is also indicated.
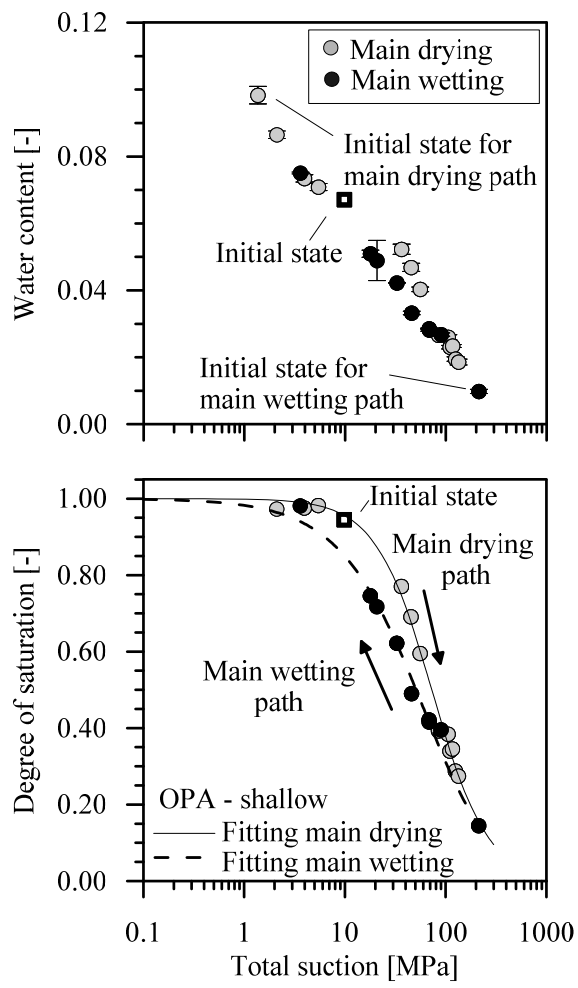

Fig.3. Water retention behaviour of the OPA-shallow core sample: the water content and degree of saturation as a function of the total suction.
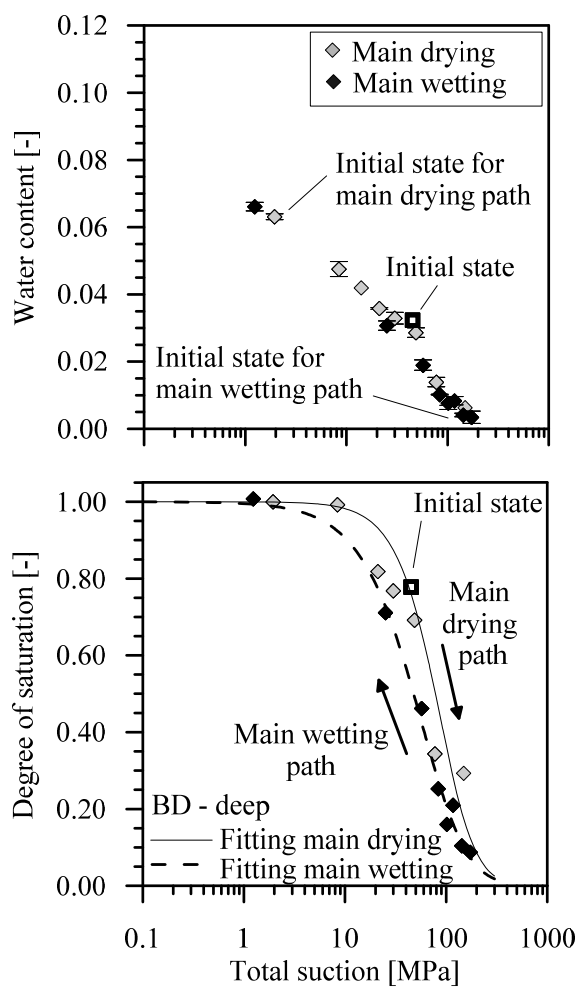

Fig.4. Water retention behaviour of the $\mathrm{BD}$ core sample: the water content and degree of saturation as a function of the total suction. 


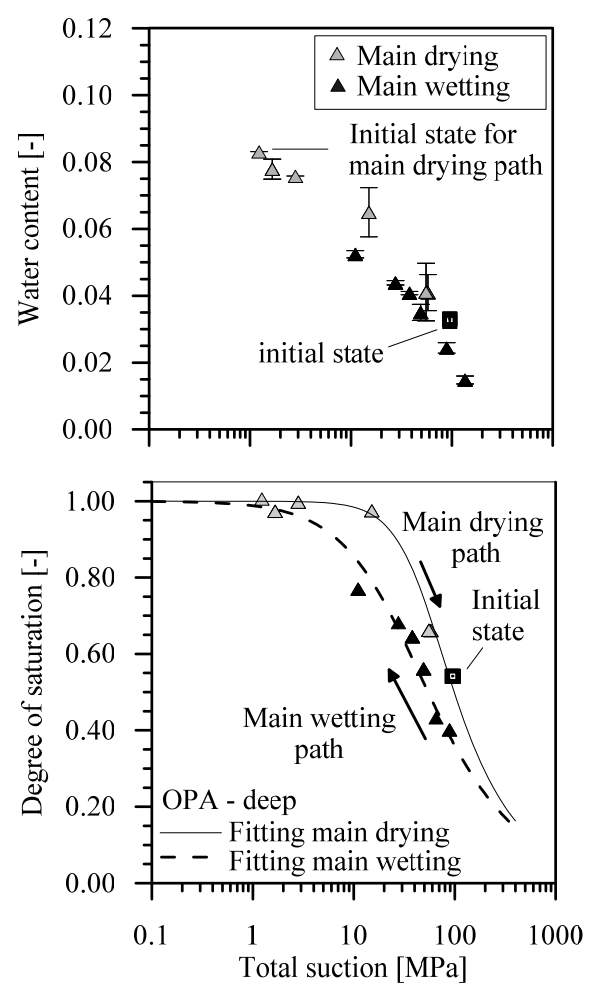

Fig.5. Water retention behaviour of the OPA-deep core sample: the water content and degree of saturation as a function of the total suction.

For the specimens equalized to the "zero matric suction" state, the measured total suction was 1.4 MPa for the Opalinus Clay-shallow and 1.2 MPa for the BD-deep and OPA-deep shales, which is in good agreement with the osmotic suction of the synthetic waters used for this initial wetting. The drying paths tend to the residual condition that was achieved in the desiccator, when the initial state for the main wetting path was sought. The initial state is found for all the materials along the main drying paths; this observation is related to the effect of the desaturation, which is a consequence of the coring process and of the exposure to atmosphere before preservation.

The retention curves in terms of degree of saturation were obtained by combining the measurements of the volume evolution and the water content along the wetting and drying paths. The results have been fitted with a Van Genuchten's type [9] expression:

$S_{r}=\left(1+\left(\frac{\Psi}{P}\right)^{n}\right)^{(-\lambda)}$

where $P, n$ and $\lambda$ are the fitting parameters; the obtained values are reported in Table 2 . The main drying path allows for the identification of the maximum total suction value that the material can sustain without significant changes in the degree of saturation (air entry value). This value (taken as the total suction corresponding to $95 \%$ of the degree of saturation) is 11 MPa for the OPA-shallow, $18 \mathrm{MPa}$ and $21 \mathrm{MPa}$ for the OPA-deep and for the BD-deep shales, respectively. A general comparison of the retention behaviour of the tested shales reveals that very limited changes in the gravimetric water content are required for the deeper shales to undergo complete cycles of wetting and drying.

Table 2: The fitting parameters for the water retention behaviour.

\begin{tabular}{|l|c|c|c|}
\hline Shale & OPA-shallow & BD-deep & OPA-deep \\
\hline \hline$n$ wetting (-) & 0.98 & 1.31 & 1.16 \\
\hline$n$ drying (-) & 1.53 & 1.85 & 2.05 \\
\hline$\lambda$ wetting (-) & 1.80 & 2.82 & 0.63 \\
\hline$\lambda$ drying (-) & 1.08 & 2.10 & 0.42 \\
\hline$P$ wetting (MPa) & 110.13 & 126.20 & 30.00 \\
\hline$P$ drying (MPa) & 78.17 & 130.00 & 49.00 \\
\hline
\end{tabular}

In order to gain additional information on the retention behaviour with cyclic variations of the water content, a wetting path was initiated for OPA-deep, starting directly from the initial state. When the retention behaviour is sought only in terms of water content by a progressive wetting and drying procedure on a single specimen, and thus a systematic analysis of the void ratio evolution with total suction is not possible, a unique trend is used to describe the swelling/shrinkage behaviour and to compute the degree of saturation. The trend is obtained by fitting the results of the void ratio variation with total suction obtained from the previous measurements of the volume evolution with suction. Such procedure is adopted since the information regarding the volumetric behaviour of the OPA-deep subjected to the progressive wetting-drying (initial void ratio and free swelling behaviour) aligned well with the trend registered for the studied shales (Fig.6).

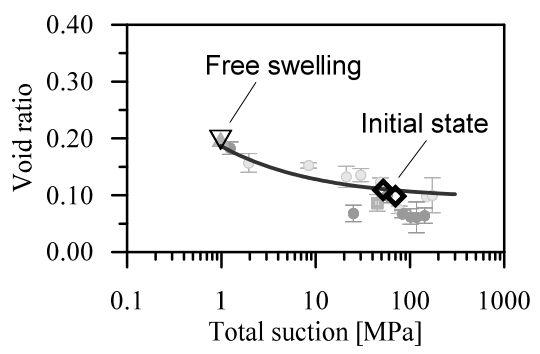

Fig.6. Good agreement of the volumetric behaviour (free swelling) of the OPA-deep sample subjected to the progressive procedure (black dots) with the trend highlighted for the analysed deep shales (grey dots).

The results of the retention behaviour in terms of water content, obtained using the progressive wetting-drying procedure, are presented in Fig.7. Three specimens were used, and they were progressively wetted until the material stopped showing a further tendency to absorb water. The corresponding total suction at this stage was approximately $2 \mathrm{MPa}$. The drying path was then initiated and carried out until a suction of $340 \mathrm{MPa}$ was reached. 


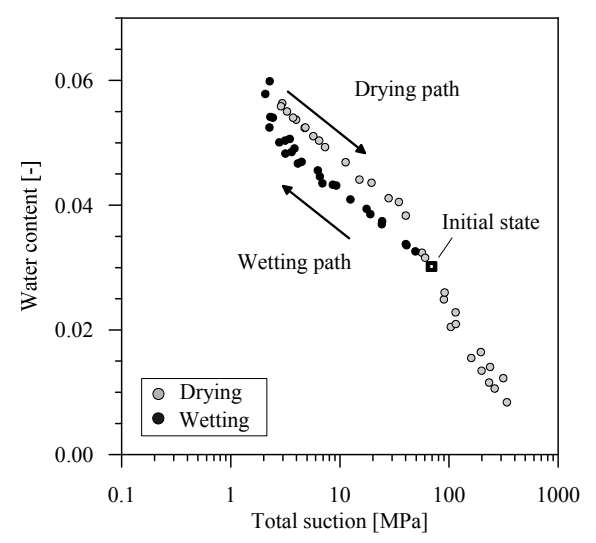

Fig.7. Water retention behaviour of the OPA- deep core sample in terms of water content versus total suction.

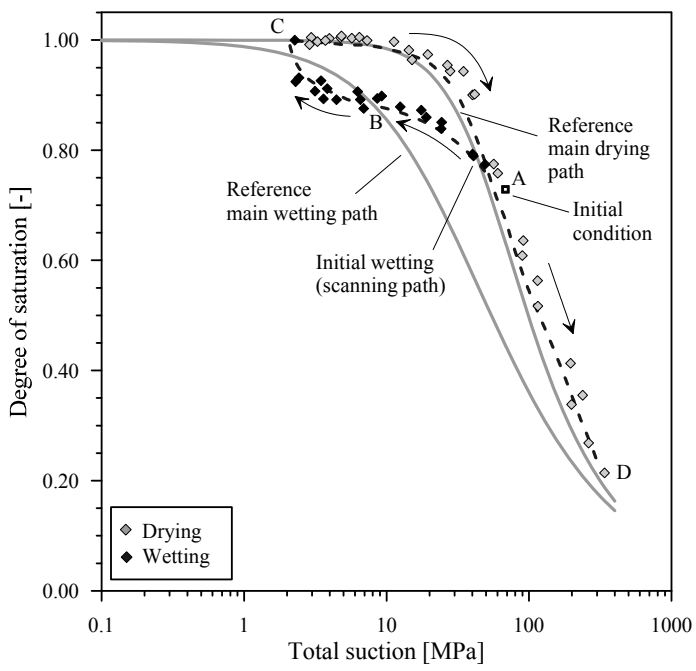

Fig.8. Retention behaviour of an Opalinus Clay sample (OPAdeep) during wetting and drying cycling.

The results obtained in terms of degree of saturation versus total suction are represented in Fig.8. In Fig. 8 the reference main wetting and main drying paths of the retention curve for the OPA-deep are also represented. The initial wetting from the initial state (path A-B) takes place inside the hysteresis domain, and a scanning curve is clearly observed. As the hydraulic path encounters the main wetting curve, it follows this trend until saturation is reached (point $\mathrm{C}$ ). Starting from this state, the hydraulic path follows the main drying path until the residual degree of saturation is reached (path $\mathrm{C}-\mathrm{D}$ ). The observed behaviour shows clearly that attention must be paid when wetting the shale, starting from its "asextracted" state.

\section{CONCLUSIONS}

The paper presented the experimental techniques that have been developed by the authors for the analysis of the water retention behaviour of shales. Selected experimental results for three shales from the northern region of Switzerland have been presented and discussed.
The elaborated testing procedure for the determination of the water retention curves of shales consisted in controlling the water content by the addition of synthetic water or by the desiccation of the material in a desiccator. Total suction measurements are performed through the use of a dew-point psychrometer, while the sample volume changes along the wetting and drying paths can be assessed to identified the evolution trend of the void ratio with total suction and thus to compute the degree of saturation of the material.

The proposed techniques have been shown to be capable of capturing the important features of the retention behaviour, such as the hysteresis domain and the existence of scanning paths when the shale is initially rewetted from its after-extraction state. The assessment of the volume change due to suction variation has allowed to express the retention behaviour in terms of degree of saturation and to capture the air entry value along the main drying paths.

\section{REFERENCES}

1. Ferrari A., V. Favero and L. Laloui. 2014. An insight into the water retention behaviour of shales. Submitted to the International Journal of Rock Mechanics and Mining Science.

2. Pearson, F.J. 1998. Opalinus Clay experimental water: A1 Type, Version 980318. PSI Internal report TM-4498-07, Paul Scherrer Institut, Villigen PSI, Switzerland.

3. Mäder U. 2011. Recipe and preparation of a simplified artificial pore water for Opalinus Clay and Brown Dogger. NAGRA AN 11-159

4. Ferrari, A. and L. Laloui. 2012. Advances in the Testing of the Hydro-mechanical Behaviour of Shales. In Multiphysical Testing of Soils and Shales, Springer Series in Geomechanics and Geoengineering, 57-68.

5. Leong, E.-C., S. Tripathy and H. Rahardjo. 2003. Total suction measurement of unsaturated soils with a device using the chilled-mirror dew point technique. Géotechnique, 53, 2: 173-182.

6. Cardoso, R., E. Romero, A. Lima and A. Ferrari. 2007. A comparative study of soil suction measurement using two different high-range psychrometers modeling of cracking and failure in brittle rocks. In Schanz, T. (Ed.) 2nd Int. Conf. on Mech. of Unsat. Soils, Weimar (Germany). Springer-Verlag, 79-93. Berlin (Germany).

7. Thomson, W. 1871. On the equilibrium of vapour at a curved surface of liquid, Phil. Mag. 42: 448-452.

8. Peron, H., T. Hueckel and L. Laloui. 2007. An improved volume measurement for determining soil water retention curves, Geotechnical Testing Journal, vol. 30 no. $1: 1-8$

9. Van Genuchten, M. Th. 1980. A closed-form equation for predicting the hydraulic conductivity of unsaturated soils. Soil Sci. Soc. Am. J., 44: 892-898 